\title{
An Increased Capacity for Adrenal DHEA Release is Associated with Decreased Avoidance and Negative Mood Symptoms in Women with PTSD
}

\author{
Ann M Rasmusson*,', Jitka Vasek², Deborah S Lipschitz', Dolores Vojvoda', Mary Ellen Mustone², \\ Quihu Shi ${ }^{3}$, Gretchen Gudmundsen ${ }^{2}$, Charles A Morgan', Jessica Wolfe ${ }^{2}$ and Dennis S Charney ${ }^{4}$ \\ 'Department of Psychiatry, Yale University School of Medicine \& VA National Center for PTSD, Clinical Neuroscience Division, VA Boston \\ Healthcare System, West Haven, CT, USA; ' ${ }^{2}$ epartment of Psychiatry, Boston University School of Medicine \& VA National Center for PTSD, \\ Womens' Health Sciences Division, VA Boston Healthcare System, Boston, MA, USA; ${ }^{3}$ School of Public Health, New York Medical College, \\ The Learning Center, Valhalla, NY, USA; ${ }^{4}$ Mood and Anxiety Disorders Branch, National Institute of Mental Health, Bethesda, MD, USA
}

We recently found increased adrenal cortisol responses to adrenocorticotropic hormone $(\mathrm{ACTH})_{\mathrm{I}-24}$ and increased pituitary ACTH and adrenal cortisol responses to corticotropin-releasing factor in premenopausal women with chronic post-traumatic stress disorder (PTSD) compared to healthy nontraumatized subjects. This pattern of hypothalamic-pituitary-adrenal axis (HPA) hyper-reactivity has been previously seen in healthy individuals treated with the antiglucocorticoid mifepristone. We therefore investigated whether endogenous plasma levels of antiglucocorticoids such as dehydroepiandrosteroine (DHEA) and progesterone were increased in premenopausal women with PTSD at baseline or in response to adrenal activation by $\mathrm{ACTH} \mathrm{H}_{1-24}$. The study revealed that DHEA responses to $250 \mu \mathrm{g}$ ACTH $\mathrm{H}_{-24}$ were increased in 13 PTSD subjects compared to 13 healthy nontraumatized subjects, while DHEA levels were generally

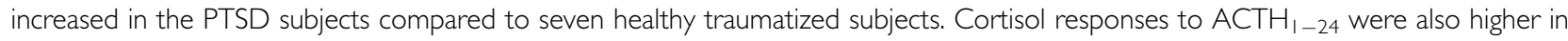
the women with PTSD, while progesterone levels and responses were not different among the three groups. In addition, among the PTSD subjects, the peak change in DHEA in response to $A C T H_{1-24}$ was negatively correlated with the total Clinician Administered PTSD Scale score, while the peak DHEA to cortisol ratio was inversely associated with negative mood symptoms measured by the Profile of Mood States scale. This work suggests that an increased capacity for DHEA release in response to extreme adrenal activation may influence the pattern of HPA axis adaptation to extreme stress, as well as mitigate the severity of PTSD and negative mood symptoms in premenopausal women with PTSD.

Neuropsychopharmacology (2004) 29, 1546-1557, advance online publication, 16 June 2004; doi: I 0. I 038/sj.npp. 1300432

Keywords: post-traumatic stress disorder; PTSD; cortisol; DHEA; premenopausal women; HPA axis

\section{INTRODUCTION}

We recently reported increased adrenal cortisol responses to intravenously administered adrenocorticotropic hormone $(\mathrm{ACTH})_{1-24}$ in premenopausal women with chronic post-traumatic stress disorder (PTSD) compared to healthy nontraumatized subjects (Rasmusson et al, 2001). In addition, we observed increased pituitary ACTH and adrenal cortisol responses to intravenously administered

\footnotetext{
*Correspondence: Dr A M Rasmusson, Psychiatry Service/II6A, VA Connecticut Healthcare System, 950 Campbell Avenue, West Haven, CT 065 I6, USA, Tel: 203-932-57I I, ext. 2483 or 2464, Fax: 203-9373886, Page 203-867-3। 32, E-mail: ann.rasmusson@yale.edu Received 22 September 2003; revised 8 January 2004; accepted 27 January 2004

Online publication: I 3 February 2004 at http://www.acnp.org/citations/ Npp02130403432/default.pdf
}

ovine corticotropin-releasing factor (CRF) in the PTSD group. While these findings are inconsistent with some previous studies showing low (Mason et al, 1986, Yehuda et al, 1990, 1993, 1995) or the same cortisol output (Kosten et al, 1990; Baker et al, 1999; Mason et al, 2002) in PTSD compared to healthy subjects, they are consistent with other studies finding relatively increased urinary free cortisol output in premenopausal women (Rasmusson et al, 2001; Lemieux and Coe, 1995; Friedman et al, 2001), mixed-sex samples of children (De Bellis et al, 1999) or adults (Maes et al, 1998), and male combat veterans (Pitman and Orr, 1990) with PTSD. Since high levels of cortisol may contribute to alterations in the structure and function of brain areas and neurotransmitter systems thought to be involved in the mediation of PTSD symptoms (Sapolsky, 1985, 1986; McEwen, 2000; Schulkin et al, 1998; Grundemann et al, 1998; Lupien et al, 1998, 1999; Newcomer et al, 
1999; Gold et al, 2002), we decided it would be important to investigate the possible mechanisms underlying increased cortisol reactivity in premenopausal women with PTSD.

Increased ACTH and cortisol responses to CRF administration have been observed in animals and humans treated with the antiglucocorticoid RU486 (Van Haarst et al, 1996; Bertagna et al, 1994). Facilitation of HPA axis reactivity by RU486 is thought to be mediated by antagonism of glucocorticoid negative feedback in the brain and pituitary, a resulting increase in ACTH release, and trophic effects of ACTH on the adrenal gland. Thus, we wondered whether endogenous, peripherally released steroids with antiglucocorticoid activity might play a role in enhancing pituitary and adrenal responsiveness in our female subjects with PTSD.

The endogenous steroids, dehydroepiandrosterone (DHEA) and progesterone, have been shown to have antiglucocorticoid activity in several tissues, including the brain (Chader and Reif-Leher, 1972; Kaiser et al, 1979; Bohus and DeKloet, 1981; Giesen and Beck, 1982; Daynes et al, 1990; Blauer et al, 1991; Browne et al, 1992; Araneo et al, 1993). DHEA and progesterone exert antiglucocorticoid effects at the glucocorticoid type II receptor via mechanisms distinct from classical receptor antagonism (Chou and Luttge, 1998; Morfin and Starka, 2001), while progesterone acts as a classical antagonist at mineralocorticoid (type I glucocorticoid) receptors (reviewed in Turner, 1997). Consistent with the antiglucocorticoid characteristics of these steroids, ACTH responses to psychological stress have been shown to increase after DHEA treatment in postmenopausal women (Kudielka et al, 1998) and dexamethasone suppression of plasma cortisol levels has been shown to be reduced during the luteal phase of the menstrual cycle when progesterone levels are high (Altemus et al, 1997). DHEA and its sulfated metabolite, DHEAS, also positively modulate NMDA receptor function and antagonize GABAA receptormediated chloride ion flux (Baulieu and Robel, 1998) - effects that may contribute to increased HPA axis responses (Barbaccio et al, 2001).

DHEA is secreted episodically and synchronously with cortisol in response to fluctuating ACTH levels (Rosenfeld et al, 1971). In addition, the administration of CRF and ACTH has been shown to increase plasma DHEA and progesterone levels (Parker et al, 1985a, b; Genazzani et al, 1998). We therefore hypothesized that premenopausal women with chronic PTSD would have increased DHEA and/or progesterone levels at baseline or in response to adrenal activation. This would be of interest not only from a neuroendocrine point of view, but also because DHEA(S) has been shown protect the brain from the negative impact of stress (Kimonides et al, 1998; Bastianetto et al, 1999; Kaminska et al, 2000; Karishma and Herbert, 2002; Zhang et $a l, 2002$ ), while the pharmacological properties of these neuroactive steroids or their metabolites might allow them to modulate PTSD symptoms (Rupprecht and Holsboer, 1999). We therefore measured plasma DHEA and progesterone levels in premenopausal women with chronic PTSD compared to healthy nontraumatized (NTC), and traumaexposed (TC) subjects before and after the intravenous administration of $\mathrm{ACTH}_{1-24}$.

\section{METHODS}

\section{Subjects}

In all, 41 subjects were recruited via community and clinic advertisements in Connecticut and Boston to participate in the study. The protocol was approved by the VA Connecticut and VA Boston Healthcare System Human Studies Subcommittees; written informed consent was obtained from each subject.

Subjects were screened for current or significant past medical illness and illicit drug use via medical history, physical examination, and laboratory tests. None had identifiable endocrine syndromes and only one healthy subject reported irregular menses. All subjects were free from psychotropic medications for months to years or had never been treated with such. Subjects abstained from other medications, alcohol, and illicit drugs for at least 4 weeks before testing, except for two PTSD and two TC subjects who used steroid hormone contraception. Two PTSD, one TC, and two NTC subjects smoked 1/2-1 pack of cigarettes per day.

DSMIV PTSD Criterion A1/A2 trauma (American Psychiatric Association, 1994) exposure was assessed by use of general and early trauma inventories (ETI) (Bremner et al, 2000) (Table 1). The A1 criterion requires that a person experiences, witnesses or confronts an event or events involving actual or threatened death or serious injury or threat to the physical integrity of self or others. The A2 criterion requires that a person's response involve intense fear, helplessness, or horror. To qualify as a Criterion A2 trauma, we required that physical or sexual trauma ascertained by the ETI be scored as 'very' or 'extremely' distressing and disruptive in at least two of three domains of function (emotional, interpersonal, or school performance).

Healthy NTC subjects were evaluated psychiatrically using the non-patient edition of the Structured Clinical Interview for DSM-IV (SCID-NP) (First et al, 1995a); subjects with a current Axis I diagnosis were excluded, except for one subject with a simple phobia. PTSD and TC subjects were evaluated using the SCID-P (First et al, 1995b); subjects with current or past psychotic disorders or bipolar disorder were excluded from participation. Current co-morbid Axis I diagnoses are presented in Table 1.

Past psychiatric diagnoses among the PTSD subjects included major depression $(n=11)$, panic disorder $(n=2)$, substance abuse or dependence ( $>6$ years before participation, $n=6)$, simple phobia $(n=2)$, eating disorder $(>10$ years before participation, $n=1)$, dysthymia $(n=1)$, OCD (washing and cleaning only, $n=1$ ), and generalized anxiety disorder $(n=1)$. Two TC subjects had remote histories of single episode major depression. One NTC subject had one episode of past major depression and one a remote history of bulimia.

The PTSD, TC, and NTC subjects did not differ significantly by age: $\mathrm{F}(2,38)=1.59, \quad p=0.22 \quad$ (PTSD: $36.1+2.2$ years, TC: $33.1+4.3$ years, NTC: $30.5+2.1$ years) or weight: $\mathrm{F}(2,38)=0.65, p=0.53$ (PTSD: $162.7+10.4 \mathrm{lbs}$, TC: $150.9+10.2 \mathrm{lbs}$, NTC: $150.6+6.2 \mathrm{lbs})$. The PTSD subjects were of mixed Caucasian $(n=13)$, African American $(n=1)$, and Hispanic $(n=1)$ ethnicity. TC subjects were of mixed Caucasian $(n=4)$, African American $(n=2)$, 
Table I Current Psychiatric Diagnoses and DSMIV Criterion AI, A2 Traumas

\begin{tabular}{|c|c|c|}
\hline $\begin{array}{l}\text { Group } \\
\text { (CAPS } \\
\left.\text { score }^{a}\right)\end{array}$ & $\begin{array}{l}\text { Co-morbid } \\
\text { diagnoses }\end{array}$ & Trauma (age in years) \\
\hline \multirow[t]{4}{*}{ PTSD (74) } & MDD & Physical abuse $(2-10)^{b}$ \\
\hline & & Sexual abuse (4-5) \\
\hline & & Rape $(13,14)$ \\
\hline & & ${ }^{\mathrm{b}}$ Domestic violence (23-25) \\
\hline \multirow[t]{2}{*}{ PTSD (60) } & None & Sexual assault (6) \\
\hline & & bWitnessed atrocities (7) \\
\hline \multirow[t]{4}{*}{ PTSD $(59)^{c}$} & None & Physical abuse (2-14) \\
\hline & & Sexual abuse $(1-14)$ \\
\hline & & 'Domestic violence (18-34) \\
\hline & & Rape (28) \\
\hline PTSD (2I) & None & ${ }^{\mathrm{b}}$ Raped twice (12) \\
\hline \multirow[t]{2}{*}{ PTSD ( 18$)$} & GAD & Physical abuse (8-13) \\
\hline & & ${ }^{\mathrm{b}}$ Rape $(20)$ \\
\hline \multirow[t]{4}{*}{ PTSD $(33)^{c}$} & GAD & Physical abuse (12-17) \\
\hline & Eating disorder NOS & Rape $(13,17)$ \\
\hline & & Attempted rape (19) \\
\hline & & bPhysical assault (29) \\
\hline \multirow[t]{2}{*}{ PTSD (35) } & None & b $\sim$ Physical abuse (2-14) \\
\hline & & Sexual abuse $(11-13)$ \\
\hline \multirow[t]{2}{*}{ PTSD (33) } & None & 'Physical abuse (8-|8) \\
\hline & & ${ }^{\mathrm{b}}$ Sexual abuse $(15-18)$ \\
\hline \multirow[t]{2}{*}{ PTSD (47) } & Dysthymia & Rape (8) \\
\hline & & bDomestic violence (33) \\
\hline \multirow[t]{2}{*}{ PTSD (64) } & None & Sexual abuse $(1-7)$ \\
\hline & & bParent's death (7) \\
\hline \multirow[t]{2}{*}{ PTSD $(70)^{c}$} & None & ${ }^{b}$ Gang rape (16) \\
\hline & & Sexual abuse $(2-16)$ \\
\hline \multirow[t]{2}{*}{ PTSD (20) } & None & Physical abuse (13-15) \\
\hline & & 'Rape (14) \\
\hline \multirow[t]{2}{*}{ PTSD (36) } & MDD & 'Witnessed parent's sudden death $(10)$ \\
\hline & & ${ }^{b}$ Rape (19), near-drowning (2I) \\
\hline \multirow[t]{2}{*}{ PTSD (3I) } & None & Rape (15) \\
\hline & & bAbduction and rape (22) \\
\hline \multirow[t]{3}{*}{ PTSD (74) } & Dysthymia & Physical abuse (2-12) \\
\hline & & Sexual abuse $(2-18)$ \\
\hline & & ${ }^{\mathrm{b}}$ Gang rape (22) \\
\hline
\end{tabular}

Table I (Continued)

\begin{tabular}{|c|c|c|}
\hline $\begin{array}{l}\text { Group } \\
\text { (CAPS } \\
\text { score }^{a} \text { ) }\end{array}$ & $\begin{array}{l}\text { Co-morbid } \\
\text { diagnoses }\end{array}$ & Trauma (age in years) \\
\hline $\mathrm{TC}(14)^{\mathrm{c}}$ & Simple phobia & bMotor accident (3I) \\
\hline \multirow[t]{2}{*}{$\mathrm{TC}(12)$} & None & Physical abuse (?-17) \\
\hline & & ${ }^{\mathrm{b}}$ Rape (34) \\
\hline \multirow[t]{2}{*}{$\mathrm{TC}(0)$} & None & bWitnessed domestic violence (9) \\
\hline & & Sexual abuse (12) \\
\hline $\mathrm{TC}(3)$ & None & bWitnessed murder (15) \\
\hline $\mathrm{TC}(0)$ & None & ${ }^{\mathrm{b}}$ Combat trauma $(25)$ \\
\hline $\mathrm{TC}(0)$ & None & bWitnessed shooting (16) \\
\hline $\mathrm{TC}(0)$ & None & ${ }^{\mathrm{b}}$ Near fatal allergic reaction (I8) \\
\hline
\end{tabular}

CAPS: Clinician Administered PTSD Scale; GAD: generalized anxiety disorder MDD: major depressive disorder; OCD: obsessive compulsive disorder; MJ: marijuana; PTSD: post-traumatic stress disorder subject; TC: healthy trauma-exposed subject; NTC: healthy nontraumatized subject.

${ }^{a}$ One-week CAPS (Clinician Administered PTSD Scale) scores were ascertained at the time of the ACTH stimulation test. Subjects were instructed to report PTSD symptoms related to any of the reported AI/A2 traumas.

bIndicates DSMIV AI, A2 traumas identified as most disturbing currently. Indicates subjects (three PTSD, one TC) for whom childhood trauma was assessed using only the general trauma inventory that contained general questions regarding exposure to childhood physical or sexual abuse. $\sim$ Indicates that trauma was verified by state records.

and Asian $(n=1)$ descent. NTC subjects were of mixed Caucasian $(n=12)$, African American $(n=1)$, Asian (1), Askenazi Jewish $(n=1)$, native Greek $(n=1)$, Hispanic $(n=1)$, native Russian $(n=1)$, and subcontinental Indian $(n=1)$ ethnicity. Years of education differed significantly, but not substantially among groups: $\mathrm{F}(2,38)=4.46, p<0.02$ (PTSD: $14.2+0.54$, TC: $14.9+0.99$, NTC: $16.5+0.52$ years). All subjects but one with PTSD had completed high school.

\section{Menstrual Cycle Monitoring}

Menstrual cycle phase at the time of the ACTH stimulation test (Table 2) was determined by use of a urine test kit to detect the mid-cycle luteinizing hormone (LH) surge (Clear Plan Easy, Whitehall Laboratories, Madison, NJ). Ovulation was confirmed by measurement of plasma progesterone levels 7-14 days later (Leibenluft et al, 1994). In the data analyses, subjects on oral contraceptives were considered to be in the follicular phase.

\section{ACTH Stimulation Test}

Fifteen PTSD, 19 NTC, and seven TC subjects completed the ACTH stimulation test. Subjects were asked to fast for $4 \mathrm{~h}$ before testing. While many subjects fasted longer, the mean fasting times were not significantly different among the groups: $\mathrm{F}(2,27)=1.98, p=0.16 \quad(\mathrm{PTSD}: 8.3+1.7 \mathrm{~h}$, TC: $12.9+1.1 \mathrm{~h}$, NTC: $11.4+1.5 \mathrm{~h}$ ). Subjects also refrained from 
Table 2 Menstrual Phase During the $\mathrm{ACTH}_{1-24}$ Stimulation Test

\begin{tabular}{lccc}
\hline & Follicular & Steroid contraception & Luteal \\
\hline *Number of subjects in DHEA(S) analyses & 3 & 2 \\
PTSD & 8 & 0 & 6 \\
NTC & 7 & 2 & 1 \\
TC & 4 & & \\
& & & \\
Number of subjects in cortisol analyses & 3 & 2 \\
PTSD & 8 & 0 & 7 \\
NTC & 8 & 2 & 1 \\
TC & 4 & & \\
& & 3 & 2 \\
Number of subjects in progesterone and estrogen analyses & \\
PTSD & 8 & 0 & 0 \\
NTC & 10 & 2 & \\
TC & 4 & & \\
\hline
\end{tabular}

smoking for $4-6 \mathrm{~h}$ prior to ACTH administration. $\mathrm{ACTH}_{1-24}$ (Cosyntropin, Organon Inc.) was administered intravenously $1 \mathrm{~h}$ after IV placement between 0800 and $1630 \mathrm{~h}$, at a maximally stimulating dose of $250 \mu \mathrm{g}$. The average time of administration did not differ among groups: $\mathrm{F}(2,38)=0.41, p=0.66$ (PTSD: $1125 \mathrm{~h} \pm 30 \mathrm{~min}$, range: $0915-1615 \mathrm{~h}$; TC: $1053 \mathrm{~h} \pm 37 \mathrm{~min}$, range: $0930-1315 \mathrm{~h}$; NTC: $1144 \mathrm{~h} \pm 32 \mathrm{~min}$, range: $0815-1345 \mathrm{~h}$ ). Most of these subjects also participated in other tests designed to examine the HPA axis at different regulatory points. We thus allowed subjects to schedule their ACTH tests at their convenience since previous work by Dickstein et al (1991) had shown adrenal capacity to be unaffected by the timing of $\mathrm{ACTH}_{1-24}$ administration.

Blood samples were collected at $-15,0,+30$, and +60 min relative to the $\mathrm{ACTH}_{1-24}$ infusion. They were spun immediately in a refrigerated centrifuge and plasma was stored at $-70^{\circ} \mathrm{C}$ until hormone measurements were made. The Clinician Administered PTSD Scale (Blake et al, 1993) (CAPS-One Week Version; PTSD and TC subjects only) and Profile of Mood States scale (rated for the past week) (POMS; Educational and Industrial Testing Service, San Diego, CA) were obtained during the $30 \mathrm{~min}$ period after IV placement.

\section{Plasma Hormone Measurements}

Plasma cortisol was measured in 35 subjects, while DHEA and DHEA-S were measured in 33 subjects in the Yale Mental Health Clinical Research Laboratory. Plasma progesterone and estrogen were measured in 36 subjects in the Laboratory of Molecular Pathophysiology at the Mood and Anxiety Disorders Program, National Institute of Mental Health. Plasma cortisol was measured using an antibodycoated tube radioimmunoassay (RIA) with an inter-assay coefficient of variation (CV) of $8.2 \%$ and intra-assay CV of $<5 \%$ (DiaSorin, Inc., Stillwater, MN). Plasma DHEA and DHEA-S were measured using RIA kits supplied by Diagnostic Systems Laboratories (Webster, TX). Plasma
DHEA was determined with a sensitivity (detectability) of $0.02 \mathrm{ng} / \mathrm{ml}$, a cross-reactivity with DHEA-S of $0.02 \%$, and intra- and inter-assay CVs of 8 and $11 \%$, respectively. Plasma DHEA-S was measured with a sensitivity of $2 \mu \mathrm{g} / \mathrm{dl}$ and intra- and inter-assay CVs of 11 and 15\%, respectively. Progesterone and estrogen were measured by solid-phase RIA (Coat-A-Count, Diagnostic Products Corporation, Los Angeles, CA) with a sensitivity of $0.5 \mathrm{ng} / \mathrm{ml}$. The inter-assay $\mathrm{CV}$ varied from 5 to $12 \%$; the intra-assay $\mathrm{CV}$ was $<5 \%$.

As indicated above, the subject numbers vary among the hormone analyses. The cortisol assays were run first. Plasma was not available for two NTC subjects when the DHEA(S) assays were run. Additional NTC subjects were completed by the time the plasma progesterone and estrogen assays were run, but we no longer had access to the lab that ran the cortisol and DHEA(S) analyses. Data from all subjects meeting the inclusion criteria and completing the ACTH study and hormone measurements were included in the data analyses.

\section{Statistical Analyses}

A random effects model was used to analyze repeated hormone measurements from the ACTH stimulation test. Diagnostic group, time, and menstrual phase were included as independent variables and a compound symmetric variance structure (CS) was used in the mixed model (Diggle et al, 1994). A high-order interaction term was removed from the model if the $p$-value for this term was larger than 0.1. Although Dickstein et al (1991) showed that cortisol levels measured at $30^{\prime}$ and $60^{\prime}$ after a maximally stimulating $250 \mu \mathrm{g}$ ACTH dose are not affected by the time of testing, baseline cortisol and DHEA levels (Erosheva et al, 2000) are known to progressively decrease from early morning until late afternoon. Baseline DHEA(S) levels are also known to decrease over the age range of subjects in the study (Hornsby, 1995). Therefore, the time of the $\mathrm{ACTH}_{1-24}$ injection and subject age were used as covariates. If there was a statistically significant difference in the overall model, pair-wise comparisons were conducted for the PTSD vs NTC, and PTSD vs TC groups; a closed testing procedure was applied to the pair-wise models.

A one-way analysis of variance (ANOVA) was used to compare the baseline or peak cortisol and DHEA hormone values among groups. The time of the $\mathrm{ACTH}_{1-24}$ injection was used as a covariate for the baseline but not peak steroid level analyses (Dickstein et al, 1991); age was also used as a covariate for the DHEA(S) analyses.

Pearson correlations were performed between age and DHEA(S) levels. Since the symptom ratings scores were not distributed normally, Spearman correlations were performed between DHEA or cortisol measures and symptom ratings. Due to the high degree of colinearity among rated psychiatric symptoms, as well as among the hormone responses to ACTH stimulation, Bonferroni corrections may impose a high risk of Type II error. Therefore, significance was set at $p<0.05$ for the main correlations between DHEA or cortisol measures in response to ACTH and the total CAPS or total POMS scores. Bonferroni corrections were used in correlations between DHEA or cortisol reactivity to ACTH and the CAPS subscales or 
component symptoms. Descriptive statistics are expressed as group means with standard errors of the mean.

It should be noted that this is not a replication study; the sample of subjects in the cortisol analysis is not independent from that in our previously published paper (Rasmusson et al, 2001). Two healthy NTC subjects and the subjects in the TC group were studied subsequent to completion of the previous study. Their data were added to the cortisol data from the previous group, and the data from this larger sample were reanalyzed.

\section{RESULTS}

\section{Plasma DHEA and DHEAS Responses to ACTH Administration}

Analysis of the ACTH stimulation test results indicated that age had a significant effect on plasma DHEA levels: $\mathrm{F}(1,28)=14.32, p<0.0007$, and correlated negatively with baseline plasma DHEA levels: $r=-0.58, p<0.0005$. There was no effect of menstrual phase on absolute DHEA levels or responses to $\mathrm{ACTH}_{1-24}$; therefore, menstrual phase was removed from the model. As expected, plasma DHEA levels increased in response to $\mathrm{ACTH}_{1-24}$ administration: $\mathrm{F}(2,59)=39.04, p<0.0001$ (Figure 1a). In addition, there was an effect of diagnosis: $\mathrm{F}(2,28)=7.21, p<0.004$, as well as a diagnosis by time interaction: $\mathrm{F}(4,59)=2.96, p<0.03$. Post hoc testing indicated that plasma DHEA levels were higher across all time points: $\mathrm{F}(1,22)=12.87, p<0.002$, and increased more in response to $\mathrm{ACTH}_{1-24}: \mathrm{F}(2,47)=4.93$, $p<0.012$, in the PTSD group compared to the NTC group. Plasma DHEA levels were higher across all time points in the PTSD group compared to the TC group: $\mathrm{F}(1,16)=7.82$, $p<0.013$, but there was no significant difference between these two groups in the DHEA response to $\mathrm{ACTH}_{1-24}$ : $\mathrm{F}(2,36)=1.40, p=0.26$. Baseline plasma DHEA levels were not significantly different among the PTSD, TC, and NTC groups: $\mathrm{F}(2,27)=1.66, p=0.21$. There were, however, differences in peak DHEA levels among the three groups: $\mathrm{F}(2,27)=9.34, \quad p<0.0009$. Peak DHEA levels after $\mathrm{ACTH}_{1-24}$ were higher in the PTSD group than in either the NTC group: $\mathrm{F}(1,27)=16.67, p<0.0005$, or the TC group: $\mathrm{F}(1,27)=9.51, p<0.005$.

We also measured the effects of ACTH on the sulfated metabolite of DHEA. As expected, age influenced plasma DHEAS levels during the ACTH test: $F(1,28)=11.46$, $p<0.003$, and correlated negatively with baseline DHEAS levels: $r=-0.52, p<0.003$. While DHEAS levels increased in response to $\mathrm{ACTH}_{1-24}$ administration: $\mathrm{F}(2,60)=7.08$, $p<0.002$, DHEAS responses to ACTH were similar among the three groups: $\mathrm{F}(4,60)=0.46, p=0.77$. We did not find a significant difference among the three groups in DHEAS levels either: $\mathrm{F}(2,28)=1.43, p=0.26$; however, the study is underpowered and we cannot rule out Type II error.

\section{Plasma Cortisol Responses to ACTH Administration}

Consistent with previous work by Kirschbaum et al (1999), menstrual phase had no effect on plasma cortisol levels or responses to $\mathrm{ACTH}$, and was removed from the model. As expected, plasma cortisol increased in response to $\mathrm{ACTH}_{1-24}: \mathrm{F}(2,63)=222.41, p<0.0001$ (Figure 1b). There
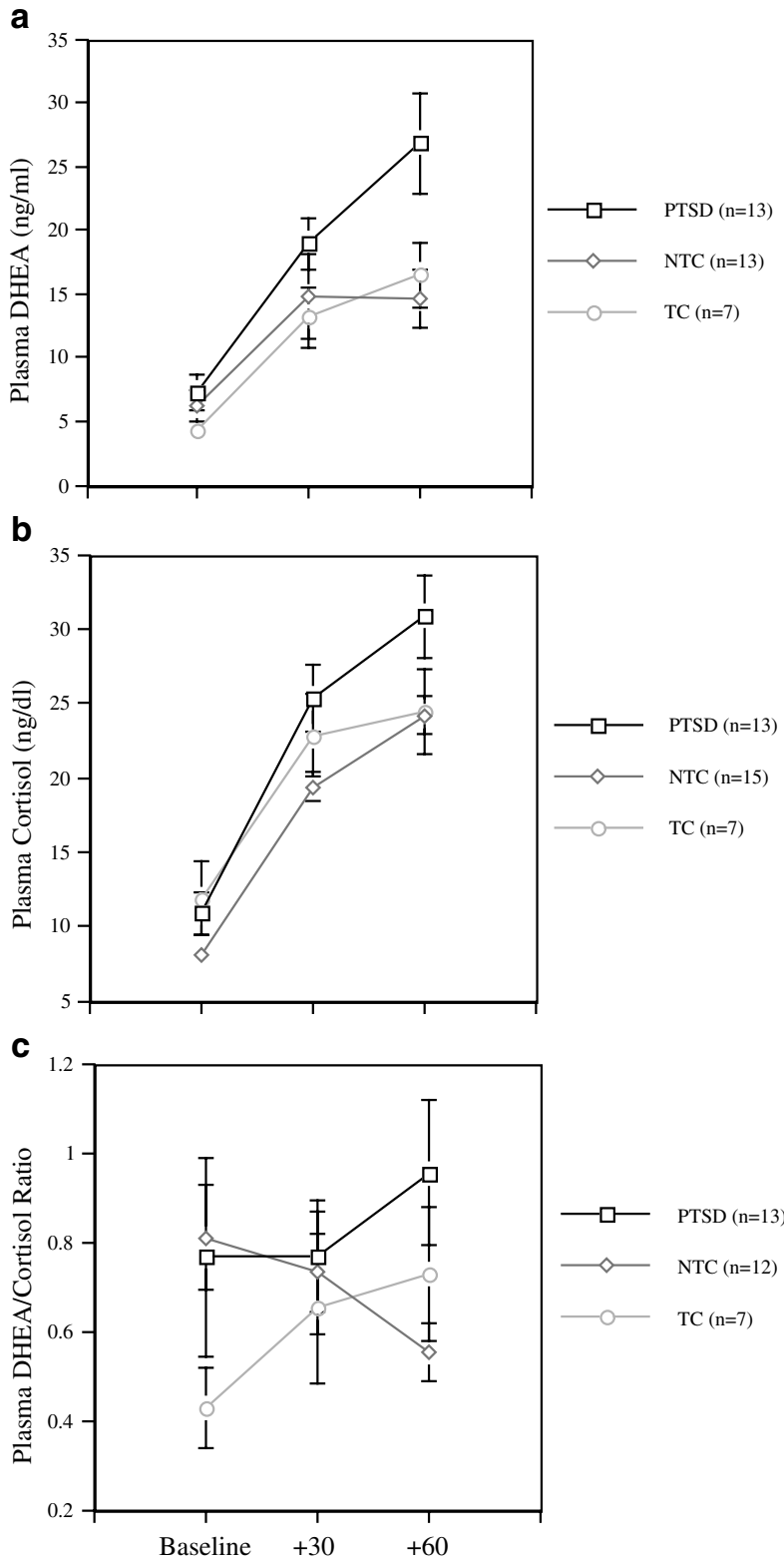

Minutes From ACTH1-24 Injection $(250 \mu \mathrm{g}$ IV)

Figure I Plasma DHEA (a), cortisol (b), and DHEA/cortisol ratios (c) in response to a maximally stimulating $250 \mu \mathrm{g}$ dose of adrenocorticotropic hormone $(\mathrm{ACTH})_{\text {I-24. }}$ PTSD: post-traumatic stress disorder; NTC: nontraumatized comparison; TC: trauma-exposed comparison subjects.

was also a significant diagnosis by time interaction: $\mathrm{F}(4,63)=3.01, p<0.025$. Post hoc pair-wise testing indicated that cortisol increased more in the PTSD than the TC group after $\mathrm{ACTH}_{1-24}: \mathrm{F}(2,36)=4.30, p<0.03$. Consistent with our previous report (Rasmusson et al, 2001), plasma cortisol levels were higher across all time points in the PTSD compared to the NTC group: $\mathrm{F}(1,24)=4.38, p<0.05$, but there was no significant difference between these groups in the slope of the cortisol response to $\mathrm{ACTH}_{1-24}$ : $\mathrm{F}(2,51)=2.11, p=0.13$. Baseline cortisol levels measured prior to $\mathrm{ACTH}_{1-24}$ administration were not significantly different among the PTSD, TC, and NTC groups: $\mathrm{F}(2,27)=1.63, p=0.22$. 


\section{The Ratio of Plasma DHEA to Cortisol}

There was a significant diagnosis by time effect on the ratio of DHEA to cortisol: $\mathrm{F}(2,60)=5.95, p<0.005$ (Figure 1c). Post hoc analyses indicated that the DHEA/cortisol ratio increased similarly in response to $\mathrm{ACTH}_{1-24}$ administration in the PTSD and TC groups (effect of time: $\mathrm{F}(1,36)=8.11$, $p<0.008$; diagnosis by time effect: $\mathrm{F}(1,36)=0.43, p=0.51$ ). The NTC group ratio behaved differently than the TC group (diagnosis by time effect: $\mathrm{F}(1,37)=13.21, p<0.0009)$ and the PTSD group (diagnosis by time effect: $F(1,47)=6.33$, $p<0.02)$. There were no group differences in the baseline $(\mathrm{F}(2,27)=1.84, \quad p=0.18) \quad$ or $30 \mathrm{~min} \quad(\mathrm{~F}(2,27)=1.10$, $p=0.35)$ DHEA/cortisol ratio. Group differences in the DHEA/cortisol ratio emerged $60 \mathrm{~min}$ after $\mathrm{ACTH}_{1-24}$ administration: $\mathrm{F}(2,27)=6.91, p<0.004$, at which time the PTSD group ratio was significantly greater than the NTC group ratio $(p<0.04)$, while the TC group ratio fell between these groups.

\section{Progesterone and Estrogen Responses to ACTH Administration}

As expected, progesterone levels varied across the menstrual cycle and were about an order of magnitude higher in the luteal compared to the follicular phase in all groups: $\mathrm{F}(1,29)=68.24, p<0.0001$. Progesterone levels appeared to change in response to $\mathrm{ACTH}_{1-24}: \mathrm{F}(2,58)=5.14, p<0.009$, but there was a significant menstrual phase by time interaction: $\mathrm{F}(2,58)=12.39, p<0.0001$. Consistent with the work by Kruyt and Rolland (1982), increases in progesterone after ACTH stimulation were detectable during the follicular phase: $\mathrm{F}(1,45)=132.93, p<0.0001$, but not during the luteal phase: $\mathrm{F}(1,15)=0.10, p=0.76$. There were no differences among the three diagnostic groups in baseline progesterone levels: $\mathrm{F}(2,26)=1.38$, $p=0.27$, or responses to $\mathrm{ACTH}_{1-24}: \mathrm{F}(4,56)=0.69$, $p=0.61$.

Plasma estrogen levels were not different between menstrual phases: $\mathrm{F}(1,34)=0.8, p=0.38$, and did not change in response to $\mathrm{ACTH}_{1-24}$ administration: $\mathrm{F}(2,67)=1.51, p=0.23$. There were also no differences among the three diagnostic groups in estrogen levels: $\mathrm{F}(2,31)=0.17, \quad p=0.84, \quad$ or reactivity to $\mathrm{ACTH}_{1-24}$ : $\mathrm{F}(4,65)=0.76, p=0.55$.

\section{Correlation of Clinical Symptoms with Plasma Hormone Responses}

As expected, there was a positive correlation between the peak change in cortisol and peak change in DHEA after $\mathrm{ACTH}_{1-24}$ administration among all subjects: $r=0.48$, $p<0.006$. The peak change in cortisol in response to $\mathrm{ACTH}_{1-24}$ correlated positively and significantly with total POMS score: $r=0.41, p<0.03$, whereas the peak change in DHEA did not: $r=0.22, p=0.26$.

Within the PTSD group, the peak change in DHEA correlated negatively with the total CAPS score: $r=-0.57$, $p<0.04$ (Figure 2a). This relationship appears to have been carried largely by a significant negative correlation between DHEA reactivity and Criterion $C$ avoidance symptoms: $r=-0.70, p<0.008$ (Figure 2b). Relationships between
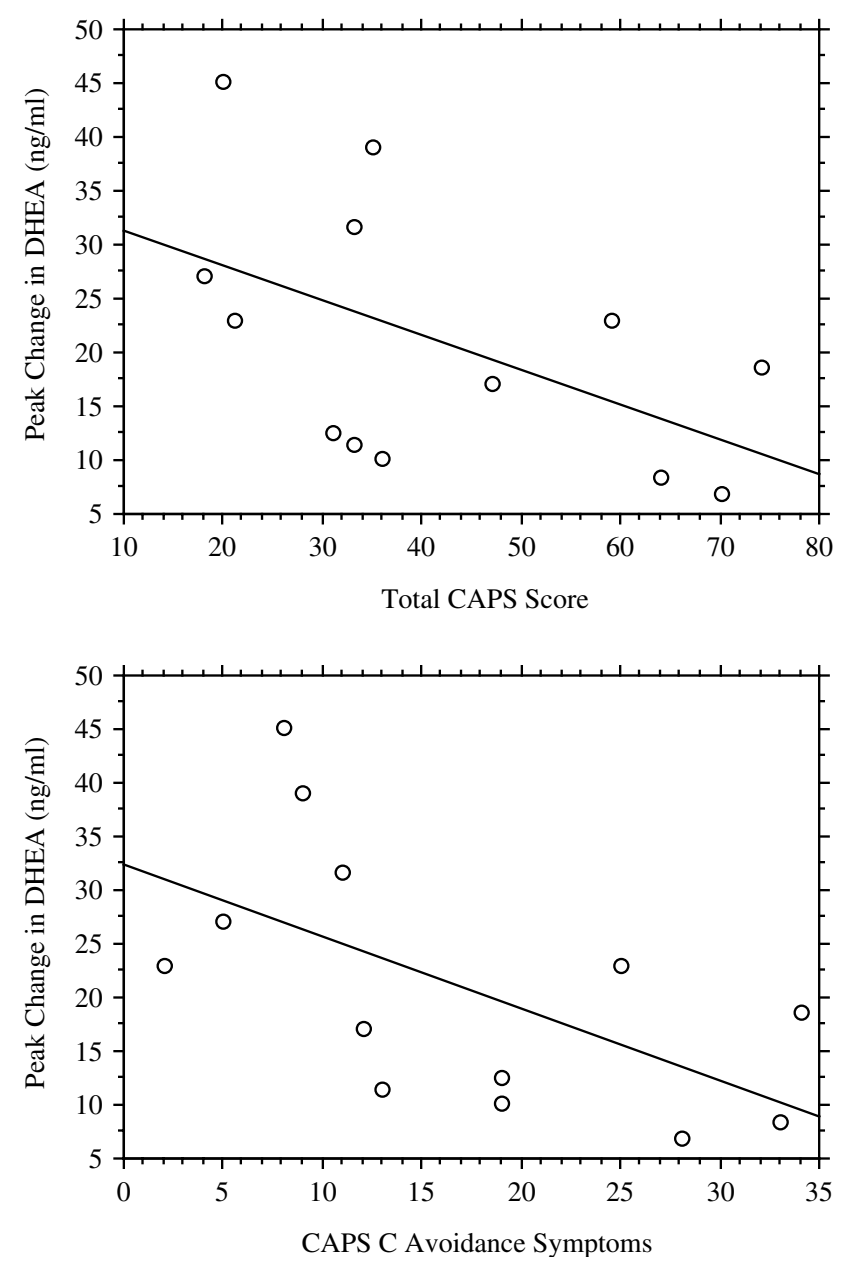

Figure 2 Scattergrams of the correlations between the peak change in plasma DHEA levels in response to $250 \mu \mathrm{g} \mathrm{ACTH}_{1-24}$ and: (a) total CAPS symptoms (Spearman $r=-0.57, p<0.04$ ), (b) CAPS C avoidance symptoms (Spearman $r=-0.70, p<0.008$ ), and (c) CAPS D hyperarousal symptoms (Spearman $r=-0.53, p=0.06$ ).

DHEA reactivity and Criterion D hyperarousal symptoms: $r=-0.53, p=0.06$ (Figure 2c), or Criterion B re-experiencing symptoms: $r=-0.19, p=0.53$, were not significant. Of note, the peak change in DHEA correlated negatively, though not necessarily significantly, with each PTSD symptom comprising the Criterion $\mathrm{B}, \mathrm{C}$, and $\mathrm{D}$ clusters, except for 'difficulty falling or staying asleep' $(r=0.52$, $p<0.08)$. Without inclusion of the sleep disturbance item in the total Criterion D symptom score, the correlation between Criterion D symptoms and the peak change in DHEA was strong and significant: $r=-0.81, p<0.0009$.

In addition, within the PTSD group, there was a negative correlation between the mean DHEA/cortisol ratio after $\mathrm{ACTH}_{1-24}$ and the POMS scores: $r=-0.63, p<0.04$. There were no significant correlations between the peak change in cortisol in response to ACTH and total CAPS scores, summed Criterion B, C, or D scores, or total POMS scores in the PTSD subjects. However, the peak change in cortisol did correlate negatively, strongly, and significantly with 'decreased interest and participation in everyday activities': $r=-0.80, p=0.001$. 


\section{DISCUSSION}

In this study, we used a standard $\mathrm{ACTH}_{1-24}$ stimulation test to assess the maximum capacity of the adrenal gland for cortisol, DHEA, and progesterone release in premenopausal women with PTSD compared to healthy nontraumatized and trauma-exposed comparison subjects. This dose of ACTH elicits cortisol responses that equal or exceed those associated with extreme naturalistic stressors with the potential to cause PTSD (reviewed in Morgan et al, 2000). We found adrenal DHEA release to be increased in the women with PTSD compared to the healthy nontraumatized subjects, while the PTSD subjects had higher DHEA levels across all time points compared to the healthy traumaexposed subjects. These findings are consistent with those of Lemieux and Coe (1995) showing an increase in 24-h urinary 17-ketosteroid metabolites of DHEA and DHEAS in premenopausal women with PTSD. They also may be consistent with two studies showing increased morning 'baseline' DHEA(S) levels in PTSD, since morning DHEA and cortisol levels reflect the reactivity of the adrenal gland to large pulses of endogenous ACTH. Spivak et al (2000) found high morning plasma DHEA and DHEAS levels, as well as a trend for an increase in plasma cortisol levels in Israeli males with combat-related PTSD. Sondergaard et al (2002) observed increased DHEAS levels among Kosovo refugees that developed PTSD but decreased DHEAS levels in refugees that developed PTSD and co-morbid depression. In that study, DHEAS levels were observed to increase over a 9-month period in association with increasing PTSD symptoms, particularly sleep disturbance. While we did not observe significant differences in plasma DHEAS levels between the traumatized subjects that did and did not develop PTSD in the current study, we cannot rule out Type II error due to the relatively small number of $\mathrm{TC}$ subjects.

In the current study, we also found increased cortisol responses to ACTH in the PTSD compared to healthy traumatized subjects, and higher cortisol levels in general in the PTSD compared to nontraumatized subjects. These findings are consistent with previous $24-h$ urinary free cortisol studies in premenopausal women and post-adrenarchal girls with PTSD, all of which have found increased cortisol output in the subjects with PTSD (Lemieux and Coe, 1995; Maes et al, 1998; De Bellis et al, 1999; Rasmusson et al, 2001; Friedman et al, 2001).

Our findings lead us to suggest that adrenally derived DHEA may contribute to an increase in the reactivity of the HPA axis in premenopausal women with PTSD. The antiglucocorticoid properties of DHEA may antagonize glucocorticoid negative feedback within the brain and pituitary, thereby facilitating CRF and/or ACTH release with a resulting increase in the adrenal capacity for cortisol release (Keller-Wood et al, 1984; Legradi et al, 1997; Heim et al, 2000; Rasmusson et al, 2001). This possibility is supported by studies in healthy volunteers of the glucocorticoid receptor antagonist mifepristone (RU486), which produces a pattern of pituitary and adrenal reactivity similar to that observed in our female subjects with PTSD (Van Haarst et al, 1996; Bertagna et al, 1994). This possibility is also supported by studies that have shown: (a) increased ACTH reactivity to psychosocial stress in post-menopausal women treated for 2 weeks with DHEA (Kudielka et al, 1998), (b) increased ACTH and cortisol reactivity in heterozygote carriers of 21-hydroxylase deficiency, wherein cortisol precursors are shunted into the androgenic steroid pathways (Witchel et al, 1997; Merke et al, 1999; Witchel and Lee, 1998), and (c) increased CRF-induced ACTH release in depressed post-adrenarchal, pre-pubertal children with PTSD living in adverse environments (Kaufman et al, 1997). In addition, DHEA(S) positively modulates NMDA receptor function and antagonizes $\mathrm{GABA}_{\mathrm{A}}$ receptors (Baulieu and Robel, 1998; Rupprecht and Holsboer, 1999), effects that may contribute to increased HPA axis responses (Barbaccio et al, 2001).

The current study does not support a role for adrenally derived progesterone in mediating differences in HPA axis responsivity between women with and without PTSD. However, it is important to note that the current study was not designed to determine whether progesterone derived from the ovary might play such a role. This will be important to assess in the future, since studies in healthy women have demonstrated increased ACTH and cortisol reactivity during the luteal compared to the follicular phase of the menstrual cycle (Kirschbaum et al, 1999; Altemus et al, 2001; Roca et al, 2003; Schmidt et al, 2002), effects that may be attributable to progesterone (Quinkler et al, 2003; Schmidt et al, 2002). It is also possible that antiglucocorticoid effects of progesterone play a role in differentiating patterns of HPA axis adaptation to stress between premenopausal women and other groups such as men, post-menopausal women, and pre-pubertal children. In addition, the conversion of DHEA to DHEAS, a metabolite that lacks antiglucocorticoid activity but that has more potent activity at $\mathrm{NMDA}$ and $\mathrm{GABA}_{\mathrm{A}}$ receptors, appears to be inhibited by estrogen and facilitated by testosterone (Neslter, 1996). Thus, sex- as well as reproductive status-related roles for DHEA and progesterone in regulating HPA axis responsivity may help explain why the only studies finding low or similar urinary cortisol output in PTSD subjects have been those containing men alone or post-menopausal women (Mason et al, 1986, 2002; Yehuda et al, 1990, 1993, 1995; Kosten et al, 1990; Baker et al, 1999).

\section{Negative Association between DHEA Responses and PTSD Symptoms and Negative Mood in PTSD}

Interestingly, despite the association between PTSD and high-stimulated DHEA levels in the current study, there was a negative correlation between DHEA reactivity and severity of PTSD symptoms within the PTSD group, suggesting that DHEA may protect against the development of avoidance as well as hyperarousal symptoms. A role for DHEA as a resilience factor in PTSD is thus consistent with recent observations in military personnel of a negative correlation between DHEAS/cortisol ratios and dissociation and a positive correlation between DHEAS/cortisol ratios and military performance during extreme training stress (Morgan et al, 2004). There are also several other clinical studies showing a negative association between plasma DHEA(S) levels and depressive symptoms, and/or a positive 
correlation between DHEA(S) levels and vigor or general well-being (Yaffe et al, 1998; Goodyer et al, 1998; Cruess et al, 1999; Heinz et al, 1999; Michael et al, 2000; Young et al, 2002). In addition, DHEA administration has been shown to treat depressive symptoms in individuals with major depression or adrenal insufficiency (Wolkowitz et al, 1999; Arlt et al, 1999), to reduce anxiety, depression, and negative symptoms in individuals with schizophrenia (Strous et al, 2003), and to mitigate depressive behavioral responses in genetically bred high- but not low-anxiety rats (Prasad et al, 1997).

\section{Molecular and Neuropharmacological Effects of DHEA with Relevance to PTSD}

In this context, it is important to appreciate that peripherally derived $\operatorname{DHEA}(S)$ is thought to be the only source of brain $\mathrm{DHEA}(\mathrm{S})$, since the biosynthetic pathway previously thought responsible for brain DHEA production functions only under nonphysiological conditions (Compagnone and Mellon, 2000). Within the brain, region-specific metabolism of DHEA may ultimately control the nature of DHEA effects on cognition and behavior (Rose et al, 1997). For instance, 7-hydroxylated metabolites of DHEA have been shown to interfere with the nuclear uptake of activated glucocorticoid receptors in neurons of the hippocampus (Morfin and Starka, 2001). This mechanism accords with the proposed antiglucocorticoid properties of DHEA and may confer neuroprotection in this brain region. For example, DHEA protects against excitatory amino acid- and oxidative stress-induced damage, restores cortisol-induced decre ments in long-term potentiation, regulates programmed cell death, and promotes neurogenesis in the hippocampus (Kimonides et al, 1998; Bastianetto et al, 1999; Kaminska et al, 2000; Karishma and Herbert, 2002; Zhang et al, 2002). Further research will be required to specifically determine whether and how DHEA may exert antiglucocorticoid effects in other brain regions of relevance to PTSD, such as the pituitary, hypothalamus, amygdala, and cortex. This is important since such effects may translate into behavioral alterations: genetic downregulation of brain glucocorticoid receptors has been shown to reduce anxiety-related behaviors in mice (Kellendonk et al, 2002).

It is also important to note that DHEA is a precursor for testosterone and estrogen, steroids with independent potent effects on brain, the HPA axis, and behavior (McEwen, 2002; Viau, 2002). In addition, pharmacological effects of DHEA or DHEAS may influence the PTSD phenotype. As Spivak et al (2000) suggested, DHEA(S) may potentiate activation of monoamine systems during stress - and thereby contribute to the consistently observed phenomenon of noradrenergic hyper-reactivity in PTSD (Southwick et al, 1999). In addition, DHEA may antagonize the capacity of cortisol to contain some aspects of the stress response (Munck et al, 1984), perhaps explaining how noradrenergic hyperreactivity can coexist with high as well as low cortisol output in PTSD. Facilitation of NMDA receptor function by DHEA(S) may also influence the development of PTSD. Activation of NMDA receptors in the amygdala has been shown to facilitate the formation as well as extinction of conditioned fear responses (Walker and Davis, 2002).
Increased DHEA(S) responses to extreme stress, could thereby enhance the development of traumatic memories as well as contribute to their extinction during naturalistic or treatment-based trauma re-exposure (Jaycox et al, 1998).

\section{Factors that Influence DHEA Production and Release by the Adrenal Gland}

Production of DHEA by the adrenal reticularis is a speciesspecific phenomenon; rodents have little circulating DHEA and the pattern of DHEA secretion differs between human and non-human primates (Neslter, 1996). In humans, plasma DHEA levels are high at birth due to the presence of the adrenal fetal zone, drop shortly thereafter, and remain low until adrenarche (age 6-8 years). DHEA levels then rapidly increase, continue to climb through adolescence, peak in the second to third decade, and then progressively decline with further aging (Hornsby, 1995). Thus, blunted DHEA responses to traumatic stress prior to adrenarche or later in life may limit the degree to which the HPA axis can upregulate in response to stress. A lack of neuroprotection by DHEA during periods of life when DHEA levels are low may contribute to toxic effects of stress on the brain.

In the current study, disparities in the frequency, severity, duration, and developmental timing of DSMIV criterion A trauma exposure between the traumatized groups with and without PTSD lead one to hypothesize that increased DHEA and cortisol reactivity may simply result from cumulative stress exposure or exposure to extreme stress earlier in life (eg, see Heim et al, 2002; Rinne et al, 2003). However, a simple effect of trauma severity or developmental timing of trauma on DHEA reactivity is not consistent with our observation of a negative correlation between DHEA reactivity and PTSD symptom severity. Other factors must also be involved.

Other proposed modulators of DHEA(S) levels during extreme stress include insulin (Bernton et al, 1995), interleukin 6 (Path et al, 1997; Judd et al, 2000), and Badrenergic receptor activation (Oberbeck et al, 1998). In addition, the current study and the work of Oberbeck et al (1998) suggest that extreme activation of the adrenal gland may result in saturation of the adrenal glucocorticoid synthetic pathway, with shunting of steroid precursors into androgen pathways. Such an effect may be magnified in individuals with functional polymorphisms of genes that code for adrenal enzymes involved in cortisol synthesis (Witchel et al, 1997; Jacobs et al, 1999).

\section{Study Limitations}

Due to the relatively low number of subjects in the trauma control group, there is inadequate statistical power to rule out significant differences in DHEA reactivity between the TC and PTSD group. We also might have expected high morning 'baseline' DHEA levels in the PTSD group; however, only about half of the subjects were studied in the morning, possibly limiting our power to detect such an effect. Variability in the time of the ACTH test does not, however, alter the confidence with which we can interpret the differences in DHEA and cortisol reactivity among 
groups. Not only did we match and covary for the time of $\mathrm{ACTH}_{1-24}$ administration across groups, but Dickstein et al (1991) demonstrated that $30^{\prime}$ and $60^{\prime}$ cortisol responses to a maximally stimulating ACTH dose do not differ between morning and late afternoon. There was also variability in the length of fasting among participants. However, there is no evidence in the literature to suggest that baseline cortisol levels vary with fasting over the interval spanned in this study. In addition, glucose effects on plasma cortisol reactivity are thought to be mediated centrally via CRF (Gonzalez-Bono et al, 2002; Heptulla et al, 2001). Adrenal steroid responses to $\mathrm{ACTH}_{1-24}$ administration do not involve CRF.

Another limitation, as well as strength, of the current study is the inclusion of only two PTSD subjects with concurrent major depression. Epidemiological data suggest that major depression co-morbid with PTSD tends to constitute more severe PTSD (Breslau et al, 2000), in part because several avoidance and hyperarousal symptoms of PTSD (poor concentration, irritability, poor sleep, decreased interest and participation in activities, and restricted range of affect) overlap with symptoms of major depression. The current findings as well as those of Sondergaard et al (2002) suggest that a group of more severely affected PTSD subjects with co-morbid major depression might show lower DHEA levels or reactivity.

It is also not clear from this cross-sectional study whether individual patterns of DHEA and cortisol output in response to adrenal activation are trait or state characteristics. Indeed, 11 PTSD subjects in the study had past major depressive episodes. It will be important to learn whether increased cortisol and DHEA reactivity in persons with PTSD predisposes to such episodes and/or whether this pattern is maintained or changes during depressive episodes and subsequent treatment (eg, see Heuser et al, 1998). The current study also does not allow us to discern whether acute and brief or more prolonged surges in DHEA are needed to affect glucocorticoid receptor function or exert effects at GABA and NMDA receptors. Our data suggest that cortisol and DHEA increases after extreme activation of the adrenal gland may persist for some time in PTSD subjects - thus research looking at the time course of these responses will be important.

And finally, while this study suggests that the adrenal release of DHEA, a compound with antiglucocorticoid activity, is increased in premenopausal women with PTSD and may interfere, for example, with glucocorticoid negative feedback within the HPA axis, the latter has not been directly demonstrated. Previous studies using the dexamethasone suppression test (DST) have shown enhanced (Stein et al, 1997) or normal (Lipschitz et al, 2003) glucocorticoid negative feedback in premenopausal women with PTSD, or have contained too few female subjects to give reliable results (Grossman et al, 2003; Rinne et al, 2002) - especially since menstrual phase influences DST outcome (Altemus et al, 1997) and was not controlled in any of these studies. Thus, it will be important in the future to investigate whether DHEA modulates glucocorticoid negative feedback at the level of the pituitary in premenopausal women with PTSD. In addition, studies in animals may be used to investigate a role for DHEA in modulating glucocorticoid negative feedback at higher levels of the central nervous system.

\section{CONCLUSION}

The current study suggests that an increased capacity for DHEA release in response to extreme adrenal activation may be protective and/or mitigate PTSD symptoms and negative mood in persons with PTSD. The results of this study should therefore spur us to examine how a shift toward androgen production, possibly influenced by genetic predisposition, as well as other biological and developmental factors, influences the pattern of neuropsychiatric and behavioral sequelae, as well as the neuroendocrine profile that develops in response to extreme stress. In addition, it will be critical to more fully understand the adaptive as well as possible maladaptive features of this pattern of neuroendocrine system adaptation (McEwen, 2000; Fabian et al, 2001). Hopefully, such work will allow us to develop new treatments for PTSD as well as new methods to identify and protect individuals at greater risk for PTSD in advance of anticipated extreme stress exposure.

\section{ACKNOWLEDGEMENTS}

This work was supported by the Veterans Affairs National Center for PTSD, Clinical Neuroscience Division in West Haven, CT, and Womens Health Science Division in Boston, MA, NIH Grant \# MH30929, the Laboratory of Molecular Pathophysiology, Mood and Anxiety Disorders Program, National Institute of Mental Health, and an ORWH/NIDA Grant \#1K12DA14038-01 (BIRWCH Award) to Dr Rasmusson. We thank Valinda Fox, RN, Willie Ford, Jill Panuzio, Angela Genovese, RNC, MBA, Elizabeth O'Donnell,RN, Kathy West, and George Anderson, $\mathrm{PhD}$, for their professional and technical support, as well as Selma Witchel, MD, for her scientific input.

\section{REFERENCES}

Altemus M, Redwine L, Leong Y-M, Yoshikawa T, Yehuda R, Detera-Wadleigh S et al (1997). Reduced sensitivity to glucocorticoid feedback and reduced glucocorticoid receptor mRNA expression in the luteal phase of the menstrual cycle. Neuropsychopharmacology 17: 100-109.

Altemus M, Roca C, Galliven E, Romanos C, Deuster P (2001). Increased vasopressin and adrenocorticotropin responses to stress in the midluteal phase of the menstrual cycle. J Clin Endocrin Metab 86: 2525-2530.

American Psychiatric Association (1994). Diagnostic and Statistical Manual of Mental Disorders 4th edn. American Psychiatric Association: Washington, DC.

Araneo BA, Shelby J, Li G-Z, Ku W, Daynes RA (1993). Administration of dehydroepiandrosterone to burned mice preserves normal immunologic competence. Arch Surg 128: 318-325.

Arlt W, Callies F, vanVlumen JC, Koehler I, Reincke M, Bidlingmaier M et al (1999). Dehydroepiandrosterone replacement in women with adrenal insufficiency. N Engl J Med 341: 1013-1020.

Baker DG, West SA, Nicholson WE, Ekhator NN, Kasckow JW, Hill KK et al (1999). Serial CSF corticotropin-releasing hormone 
levels and adrenocortical activity in combat veterans with posttraumatic stress disorder. Am J Psychiatry 156: 585-588.

Barbaccia ML, Serra M, Purdy RH, Biggio G (2001). Stress and neuroactive steroids. Int Rev Neurobiol 46: 243-272.

Bastianetto S, Ramassamy C, Poirier J, Quirion R (1999). Dehydroepiandrosterone (DHEA) protects hippocampal cells from oxidative stress-induced damage. Mol Brain Res 66: 35-41.

Baulieu E-E, Robel P (1998). Dehydroepiandrosterone (DHEA) and dehydroepiandrosterone sulfate (DHEAS) as neuroactive neurosteroids. Proc Natl Acad Sci USA 95: 4089-4091.

Bernton E, Hoover D, Galloway R, Popp K (1995). Adaptation to chronic stress in military trainees. Ann NY Acad Sci 774: 217-231.

Bertagna X, Escourolle H, Pinier JL, Coste J, Raux-Demay MC, Perles $\mathrm{P}$ et al (1994). Administration of RU 486 for 8 days in normal volunteers: antiglucocorticoid effect with no evidence of peripheral cortisol deprivation. J Clin Endocrinol Metab 78: 375-380.

Blake DD, Weathers FW, Nagy LM (1993). A clinician rating scale for assessing current and lifetime PTSD: the CAPS-I. Behav Ther 18: 187-188.

Blauer KL, Poth M, Rogers W, Bernton E (1991). DHEA antagonizes the suppressive effects of dexamethasone on lymphocyte proliferation. Endocrinology 129: 3174-3179.

Bohus B, DeKloet ER (1981). Adrenal steroids and extinction behavior: antagonism by progesterone, deoxycorticosterone and dexamethasone of a specific effect of corticosterone. Life Sci 28: 433-440.

Bremner JD, Vermetten E, Mazure CM (2000). Development and preliminary psychometric properties of an instrument for the measurement of childhood trauma: the Early Trauma Inventory. Depress Anxiety 12: 1-12.

Breslau N, Davis GC, Peterson EL, Schultz LR (2000). A second look at comorbidity in victims of trauma: the posttraumatic stress disorder-major depression connection. Biol Psychiatry 48: 902-909.

Browne ES, Wright BE, Porter JR, Svec F (1992). Dehydroepiandrosterone: antiglucocorticoid action in mice. Am J Med Sci 303: 366-371.

Chader GJ, Reif-Leher L (1972). Hormonal effects on the neural retina: corticoid uptake, specific binding and structural requirement for the induction of glutamine synthetase. Biochim Biophys Acta 264: 186-196.

Chou Y-C, Luttge WG (1998). Activated type II receptors in brain cannot rebind glucocorticoids: relationship to progesterone's antiglucocorticoid actions. Brain Res 440: 67-78.

Compagnone NA, Mellon SH (2000). Neurosteroids: biosynthesis and function of these novel neuromodulators. Front Neuroendocrinol 21: 1-56.

Cruess DG, Antoni MH, Kumar M, Ironson G, McCabe P, Fernandez JB et al (1999). Cognitive-behavioral stress management buffers decreases in dehydroepiandrosterone sulfate (DHEA-S) and increases in the cortisol/DHEA-S ratio and reduces mood disturbance and perceived stress among HIV-seropositive men. Psychoneuroendocrinology 24: 537-549.

Daynes RA, Dudley DJ, Araneo BA (1990). Regulation of murine lymphokine production in vivo, II: Dehydroepiandrosterone is a natural enhancer of IL-2 synthesis by helper T cells. Eur $J$ Immunol 19: 2319-2325.

De Bellis MD, Baum AS, Birmaher B, Keshavan MS, Eccard CH, Boring AM et al (1999). A.E. Bennett Research Award-developmental traumatology. Part I: Biological stress systems. Biol Psychiatry 45: 1259-1270.

Dickstein G, Shechner C, Nicholson WE, Rosner I, Shen-Orr Z, Adawi $\mathrm{F}$ et al (1991). Adrenocorticotropin stimulation test: effects of basal cortisol level, time of day, and suggested new sensitive low dose test. J Clin Endocrinol Metab 72: 773-778.
Diggle PJ, Liang K-Y, Zeger SL (1994). Analysis of Longitudinal Data. Oxford Science Publications: Oxford, England.

Erosheva EA, Salek FS, Stone RA, Folan MM, Greenhouse J, Kroboth PD (2000). Characterizing the diurnal rhythm of DHEA and effects of an oral dose of alprazolam. Biol Psychiatry 47: $145 \mathrm{~S}$.

Fabian TJ, Dew MA, Pollock BG, Reynolds III CF, Mulsant BH, Butters MA et al (2001). Endogenous concentrations of DHEA and DHEA-S decrease with remission of depression in older adults. Biol Psychiatry 50: 767-774.

First MB, Spitzer RL, Gibbon M, Williams JB (1995a). Structured Clinical Interview for the DSM-IV Axis I Disorders-NonPatient Edition (SCID-I/NP, Version 2.0). Biometrics Research Department, New York State Psychiatric Institute: NewYork, NY.

First MB, Spitzer RL, Gibbon M, Williams JB (1995b). Structured Clinical Interview for the DSM-IV Axis I Disorders-Patient Edition (SCID-I/P, Version 2.0). Biometrics Research Department, New York State Psychiatric Institute: NewYork, NY.

Friedman MJ, McDonagh-Coyle AS, Jalowiec JE, Wang S, Fournier DA, McHugo GJ (2001). Neurohormonal findings during treatment of women with PTSD due to childhood sexual abuse (CSA) Abstract for the 17th Annual Meeting for the International Society for Traumatic Stress Studies, New Orleans, LA. p 45.

Genazzani AR, Petraglia F, Bernardi F, Casarosa E, Salvestroni C, Tonetti A et al (1998). Circulating levels of allopregnanolone in humans: gender, age, and endocrine influences. J Clin Endocrinol Metab 83: 2099-2103.

Giesen EM, Beck G (1982). Hormonal deinduction of tyrosine aminotransferase. Horm Metab Res 14: 252-256.

Gold PW, Drevets WC, Charney DS (2002). New insights into the role of cortisol and the glucocorticoid receptor in severe depression. Biol Psychiatry 52: 381-385.

Gonzalez-Bono E, Rohleder N, Hellhammer DH, Salvador A, Kirschbaum C (2002). Glucose but not protein or fat load amplifies the cortisol response to psychosocial stress. Hormone Behav 41: 328-333.

Goodyer IM, Herbert J, Altham PME (1998). Adrenal steroid secretion and major depression in 8- to 16-year-olds, III. Influence of cortisol/DHEA ratio at presentation on subsequent rates of disappointing life events and persistent major depression. Psychol Med 28: 265-273.

Grossman R, Yehuda R, New A, Schmeidler J, Silverman J, Mitropoulou V, Maria St N, Golier J, Siever L (2003). Dexamethasone suppression test findings in subjects with personality disorders: associations with posttraumatic stress disorder and major depression. Am J Psychiatry 160: 1291-1297.

Grundemann D, Schechinger B, Rappold GA, Schomig E (1998). Molecular identification of the cortisone-sensitive extraneuronal catecholamine transporter. Nat Neurosci 1: 349-351.

Heim C, Newport DJ, Heit S, Graham YP, Wilcox M, Bonsall R et al (2000). Pituitary-adrenal and autonomic responses to stress in women after sexual and physical abuse in childhood. JAMA 284: 592-597.

Heim C, Newport DJ, Wagner D, Wilcox MM, Miller AH, Nemeroff CB (2002). The role of early adverse experience and adulthood stress in the prediction of neuroendocrine stress reactivity in women: a multiple regression analysis. Depress $A n x$ 15: $117-125$.

Heinz A, Weingartner H, George D, Hommer D, Wolkowitz OM, Linnoila M (1999). Severity of depression in abstinent alcoholics is associated with monoamine metabolites and dehydroepiandrosterone-sulfate concentrations. Psychiatry Res 89: 97-106.

Heptulla RA, Tamborlane WV, Ma TYZ, Rife F, Sherwin RS (2001). Oral glucose augments the counterregulatory hormone response during insulin-induced hypoglycemia in humans. J Clin Endocrinol Metab 86: 645-648.

Heuser I, Deuschle M, Luppa P, Schweiger U, Standhardt H, Weber $B$ (1998). Increased diurnal plasma concentrations of dehydroe- 
piandrosterone in depressed patients. J Clin Endocrinol Metab 83: $3130-3133$

Hornsby PJ (1995). Biosynthesis of DHEAS by the human adrenal cortex and its age-related decline. Ann NY Acad Sci 774: 29-46.

Jacobs AR, Edelheit PB, Coleman AE, Herzog AG (1999). Lateonset congenital adrenal hyperplasia: a treatable cause of anxiety. Biol Psychiatry 46: 856-859.

Jaycox LH, Foa EB, Morral AR (1998). Influence of emotional engagement and habituation on exposure therapy for PTSD. Ann NY Acad Sci 66: 185-192.

Judd AM, Call GB, Barney M, McIlmoil CJ, Balls AG, Adams A et al (2000). Possible function of IL-6 and TNF as intraadrenal factors in the regulation of adrenal steroid secretion. Ann NY Acad Sci 917: 628-637.

Kaiser N, Mayer M, Milholland RJ, Rosen F (1979). Studies on the anti-glucocorticoid actions of progesterone in rat thymocytes: early in vitro effects. J Steroid Biochem 10: 379-386.

Kaminska M, Harris J, Gilsbers K, Dubrovsky B (2000). Dehydroepiandrosterone sulfate (DHEAS) counteracts decremental effects of corticosterone on dentate gyrus LTP. Implications for depression. Brain Res Bull 52: 229-234.

Karishma KK, Herbert J (2002). Dehydroepiandrosterone (DHEA) stimulates neurogenesis in the hippocampus of the rat, promotes survival of newly formed neurons and prevents corticosteroneinduced suppression. Eur J Neurosci 16: 445-453.

Kaufman J, Birmaher B, Perel J, Dahl RE, Moreci P, Nelson B et al (1997). The corticotropin-releasing hormone challenge in depressed abused, depressed nonabused, and normal control children. Biol Psychiatry 42: 669-679.

Kellendonk C, Gass P, Kretz O, Schutz G, Tronche F (2002). Corticosteroid receptors in the brain: gene targeting studies. Brain Res Bull 57: 73-83.

Keller-Wood M, Shinsako J, Dallman MF (1984). Interactions between stimulus intensity and corticosteroid feedback in control of ACTH. Am J Physiology 247: E489-E494.

Kimonides VG, Khatibi NH, Svendsen CN, Sofroniew MV, Herbert J (1998). Dehydroepiandrosterone (DHEA) and DHEA-sulfate (DHEAS) protect hippocampal neurons against excitatory amino acid-induced neurotoxicity. Proc Natl Acad Sci USA 95: 1852-1857.

Kirschbaum C, Kudielka BM, Gaap J, Schommer NC, Hellhammer DH (1999). Impact of gender, menstrual cycle phase, and oral contraceptives on the activity of the hypothalamus-pituitaryadrenal axis. Psychosom Med 61: 154-162.

Kosten TR, Wahby VS, Giller E, Mason J (1990). The dexamethasone suppression and TRH stimulation tests in post traumatic stress disorder. Biol Psychiatry 28: 657-664.

Kruyt N, Rolland R (1982). Cortisol, 17 $\alpha-\mathrm{OH}-$ progesterone and androgen responses to a standardized ACTH-stimulation test in different stages of the normal menstrual cycle. Acta Endocrinol 100: 427-433.

Kudielka BM, Hellhammer J, Hellhammer DH, Wolf OT, Pirke KM, Varadi E et al (1998). Sex differences in endocrine and psychological responses to psychosocial stress in healthy elderly subjects and the impact of a two-week DHEA treatment. J Clin Endocrinol Metab 83: 1756-1761.

Legradi G, Holzer D, Kapcala LP, Lechan RM (1997). Glucocorticoids inhibit stress-induced phosphorylation of CREB in corticotropin-releasing hormone neurons of the hypothalamic paraventricular nucleus. Neuroendocrinology 66: 86-97.

Leibenluft E, Fiero PL, Rubinow DR (1994). Effects of the menstrual cycle on dependent variables in mood disorder research. Arch Gen Psychiatry 51: 761-781.

Lemieux A, Coe C (1995). Abuse-related posttraumatic stress disorder: evidence for chronic neuroendocrine activation in women. Psychsom Med 57: 105-115.
Lipschitz DS, Rasmusson AM, Yehuda R, Wang S, Anyan W, Gueoguieva R et al (2003). Salivary cortisol responses to dexamethasone in adolescents with posttraumatic stress disorder. J Am Acad Child Adol Psychiatry 42: 1310-1317.

Lupien S, deLeon M, deSanti S, Convit A, Tarshish C, Nair NPV et al (1998). Cortisol levels during human aging predict hippocampal atrophy and memory deficits. Nat Neurosci 1: 69-73.

Lupien SG, Gillin CJ, Hauger RL (1999). Working memory is more sensitive than declarative memory to the acute effects of corticosteroids: a dose-response study in humans. Behav Neurosci 113: 420-430.

Maes M, Lin A, Bonaccorso S, Van Hunsel F, Van Gastel A, Delmeire L et al (1998). Increased 24-hour urinary cortisol excretion in patients with post-traumatic stress disorder and patients with major depression, but not in patients with fibromyalgia. Acta Psychiatr Scand 98: 328-335.

Mason J, Wang S, Yehuda R, Lubin H, Johnson D, Bremner JD et al (2002). Marked lability in urinary free cortisol levels in subgroups of combat veterans with posttraumatic stress disorder during an intensive exposure treatment program. Psychosom Med 6: 234-238.

Mason JW, Giller EL, Kosten TR, Ostroff RB, Rodd L (1986). Urinary-free cortisol levels in post-traumatic stress disorder patients. J Nerv Ment Dis 174: 145-159.

McEwen B (2002). Estrogen actions throughout the brain. Recent Prog Hormone Res 57: 357-384.

McEwen BS (2000). Allostasis and allostatic load: implications for neuropsychopharmacology. Neuropsychopharmacology 22: 108-124.

Merke DP, Keil ME, Negro PJ, Gold P, Chrousos GP (1999). 21hydroxylase deficient carriers reset their hypothalamic-pituitary axis to normalize cortisol production: potential relation to mood changes leading to a selective advantage Endocrine Society Meeting Poster Abstract PI-659.

Michael A, Jenaway A, Paykel ES, Herbert J (2000). Altered salivary dehydroepiandrosterone levels in major depression in adults. Biol Psychiatry 48: 989-995.

Morfin R, Starka L (2001). Neurosteroid 7-hydroxylation products in the brain. Int Rev Neurobiol 46: 79-95.

Morgan III CA, Hazlett G, Southwick S, Rasmusson A, Hoyt G, Zimolo $\mathrm{Z}$ et al (2004). Relationships among plasma DHEA(S), cortisol, symptoms of dissociation and objective performance in humans exposed to acute stress. Arch Gen Psychiatry (in press).

Morgan III CA, Wang S, Mason J, Southwick SM, Fox P, Hazlett G, Charney DS, Greenfield G (2000). Hormone profiles in humans experiencing military survival training. Biol Psychiatry 47: 891-901.

Munck A, Guyre PM, Holbrook NJ (1984). Physiological functions of glucocorticoids in stress and their relation to pharmacological actions. Endocrine Rev 93: 9779-9783.

Neslter JE (1996). Advances in understanding the regulation and biologic actions of dehydroepiandrosterone. Curr Opin Endocrinol Diabetes 3: 202-211.

Newcomer JW, Selke G, Melson AK, Hershey T, Craft S, Richards K et al (1999). Decreased memory performance in healthy humans induced by stress-level cortisol treatment. Arch Gen Psychiatry 56: 527-533.

Oberbeck R, Benschop RJ, Jacobs R, Hosch W, Jetschmann JU, Schurmeyer TH et al (1998). Endocrine mechanims of stressinduced DHEA-secretion. J Endocrinol Invest 21: 148-153.

Parker L, Eugene J, Farber D, Lifrak E, Lai M, Juler G (1985a). Dissociation of adrenal androgens and cortisol levels in acute stress. Horm Metabol Res 17: 209-212.

Parker LN, Levin ER, Lifrak ET (1985b). Evidence for adrenocortical adaptation to severe illness. Endocrinol Metab 60: 947-952.

Path G, Bornstein SR, Ehrhart-Bornstein M, Scherbaum WA (1997). Interleukin-6 and the interleukin-6 receptor in the 
human adrenal gland: expression and effects on steroidogenesis. $J$ Clin Endocrin Metab 82: 2343-2349.

Pitman R, Orr S (1990). Twenty-four hour urinary cortisol and catecholamine excretion in combat-related posttraumatic stress disorder. Biol Psychiatry 27: 245-247.

Prasad A, Imamura M, Prasad C (1997). Dehydroepiandrosterone decreases behavioral despair in high- but not low-anxiety rats. Physiol Behav 62: 1053-1057.

Quinkler M, Meyer B, Oelkers W, Diederich S (2003). Renal inactivation, mineralocorticoid generation, and 11B-hydroxysteroid dehydrogenase inhibition ameliorate the antimineralocorticoid effect of progesterone in vivo. J Clin Endocrinol Metab 88: $3767-3772$.

Rasmusson AM, Lipschitz DS, Wang S, Hu S, Vojvoda D, Bremner JD et al (2001). Increased pituitary and adrenal reactivity in premenopausal women with PTSD. Biol Psychiatry 50: 965-977.

Rinne T, de Kloet ER, Wouters L, Goekoop JG, DeRijk RH, van den Brink W (2002). Hyperresponsiveness of hypothalamic-pituitary-adrenal axis to combined dexamethasone/corticotropinreleasing hormone challenge in female borderline personality disorder subjects with a history of sustained childhood abuse. Biol Psychiatry 52: 1102-1112.

Rinne T, deKloet ER, Wouters L, Goekoop JG, de Rijk RH, van den Brink W (2003). Fluvoxamine reduces responsiveness of HPA axis in adult female BPD patients with a history of sustained childhood abuse. Neuropsychopharmacology 28: 126-132.

Roca CA, Schmidt PJ, Altemus M, Deuster P, Danaceau MA, Putnam K et al (2003). Differential menstrual cycle regulation of hypothalamic-adrenal axis in women with premenstrual syndrome and controls. J Clin Endocrinol Metab 88: 3057-3063.

Rose KA, Stapleton G, Dott K, Kieny MP, Best R, Schwarz M et al (1997). Cyp7b, a novel brain cytochrome P450, catalyzes the synthesis of neurosteroids 7a-hydroxy dehydroepiandrosterone and 7a-hydroxy pregnenolone. Proc Natl Acad Sci USA 94: 4925-4930.

Rosenfeld RS, Hellman L, Roffwarg H, Weitzman ED, Fukushima DK, Gallagher TF (1971). Dehydroisoandrosterone is secreted episodically and synchronously with cortisol by normal man. $J$ Clin Endocrinol 33: 87-92.

Rupprecht R, Holsboer F (1999). Neuroactive steroids: mechanisms of action and neuropharmacological perspectives. Trends Neurosci 22: 410-416.

Sapolsky R (1985). A mechanism for glucocorticoid toxicity in the hippocampus: increased neuronal vulnerability to metabolic insults. J Neurosci 5: 1228-1232.

Sapolsky R (1986). Glucocorticoid toxicity in the hippocampus: synergy with an excitotoxin. Neuroendocrinology 43: 440-446.

Schmidt PJ, Raju J, Danaceau M, Murphy DL, Berlin RE (2002). The effects of gender and gonadal steroids on the neuroendocrine and temperature response to $m$-chlorophenylpiperazine in leuprolide-induced hypogonadism in women and men. Neuropsychopharmacology 27: 800-812.

Schulkin J, Gold PW, McEwen BS (1998). Induction of corticotropin-releasing hormone gene expression by glucocorticoids: implication for understanding the states of fear and anxiety and allostatis load. Psychoneuroendocrinology 23: 219-243.

Sondergaard HP, Hansson L-O, Theorell T (2002). Elevated blood levels of dehydroepiandrosterone sulphate vary with symptom load in posttraumatic stress disorder: findings from a longitudinal study of refugees in Sweden. Psychother Psychosom 71: 298-303.

Southwick SM, Bremner JD, Rasmusson A, Morgan CA, Arnsten A, Charney DS (1999). Role of norepinephrine in the pathophysiol- ogy and treatment of posttraumatic stress disorder. Biol Psychiatry 46: 1192-1204.

Spivak B, Maayan R, Kotler M, Mester R, Gil-Ad I, Shtaif B et al (2000). Elevated circulatory level of $\mathrm{GABA}_{\mathrm{A}}$-antagonistic neurosteroids in patients with combat-related post-traumatic stress disorder. Psychol Med 30: 1227-1231.

Stein MB, Yehuda R, Koverola C, Hanna C (1997). Enhanced dexamethasone suppression of plasma cortisol in adult women traumatized by childhood sexual abuse. Biol Psychiatry 42: $680-686$.

Strous R, Maayan R, Lapidus R, Stryjer R, Lustig M, Kotler M et al (2003). Dehydroepiandrosterone augmentation in the management of negative, depressive, and anxiety symptoms in schizophrenia. Arch Gen Psychiatry 60: 133141.72 .

Turner BB (1997). Influence of gonadal steroids on brain corticosteroid receptors: minireview. Neurochem Res 22: $1375-1385$.

Van Haarst AD, Oitzl MS, Workel JO, De Kloet ER (1996). Chronic brain glucocorticoid receptor blockade enhances the rise in circadian and stress-induced pituitary-adrenal activity. Endocrinology 137: 4935-4943.

Viau V (2002). Functional cross-talk between the hypothalamicpituitary-gonadal and -adrenal axes. J Neuroendocrinol 14: 506-513.

Walker DL, Davis M (2002). The role of amygdala glutamate receptors in fear learning, fear-potentiated startle, and extinction. Pharm Biochem Behav 71: 379-392.

Witchel S, Lee P (1998). Identification of heterozygotic carriers of 21-hydroxylase deficiency: sensitivity of ACTH stimulation tests. Am J Med Genet 76: 337-342.

Witchel S, Lee P, Suda-Hartman S, Trucco M, Hoffman E (1997). Evidence for a heterozygote advantage in congenital adrenal hyperplasia due to 21-hydroxylase deficiency. J Clin Endocrinol Metab 82: 2097-2101.

Wolkowitz OM, Reus VI, Keebler A, Nelson N, Friedland M, Brizendine L et al (1999). Double-blind treatment of major depression with dehydroepiandrosterone. Am J Psychiatry 156: 646-649.

Yaffe K, Ettinger B, Pressman A, Seeley D, Whooley M, Schaefer C et al (1998). Neuropsychiatric function and dehydroepiandrosterone sulfate in elderly women: a prospective study. Biol Psychiatry 43: 694-700.

Yehuda R, Boisoneau D, Mason JW, Giller EL (1993). Relationship between lymphocyte glucocorticoid receptor number and urinary-free cortisol excretion in mood, anxiety, and psychotic disorder. Biol Psychiatry 34: 18-25.

Yehuda R, Kahana B, Binder-Brynes K, Southwick S, Mason J, Giller E (1995). Low urinary cortisol excretion in holocaust survivors with posttraumatic stress disorder. Am J Psychiatry 152: 982-986.

Yehuda R, Southwick SM, Nussbaum G, Wahby V, Giller EL, Mason JW (1990). Low urinary cortisol excretion in patients with posttraumatic stress disorder. J Nerv Ment Dis 178: 366-369.

Young AH, Gallagher P, Porter RJ (2002). Elevation of the cortisoldehydroepiandrosterone ratio in drug-free depressed patients. Am J Psychiatry 159: 1237-1239.

Zhang L, Li B, Ma W, Barker JL, Chang YH, Zhao W et al (2002). Dehydroepiandrosterone (DHEA) and its sulfated derivative (DHEAS) regulate apoptosis during neurogenesis by triggering the Akt signaling pathway in opposing ways. Brain Res $\mathrm{Mol}$ Brain Res 98: 58-66. 